\title{
A framework for techno-economic \& environmental sustainability analysis by risk assessment for conceptual process evaluation
}

\author{
Loureiro da Costa Lira Gargalo, Carina; Sin, Gürkan; Carvalho, Ana; Gernaey, Krist; Sin, Gürkan
}

Published in:

Biochemical Engineering Journal

Link to article, DOI:

10.1016/j.bej.2016.06.007

Publication date:

2016

Document Version

Peer reviewed version

Link back to DTU Orbit

Citation (APA):

Loureiro da Costa Lira Gargalo, C., Sin, G., Carvalho, A., Gernaey, K., \& Sin, G. (2016). A framework for technoeconomic \& environmental sustainability analysis by risk assessment for conceptual process evaluation. Biochemical Engineering Journal, 116, 146-156. https://doi.org/10.1016/j.bej.2016.06.007

\section{General rights}

Copyright and moral rights for the publications made accessible in the public portal are retained by the authors and/or other copyright owners and it is a condition of accessing publications that users recognise and abide by the legal requirements associated with these rights.

- Users may download and print one copy of any publication from the public portal for the purpose of private study or research.

- You may not further distribute the material or use it for any profit-making activity or commercial gain

- You may freely distribute the URL identifying the publication in the public portal 


\section{Accepted Manuscript}

Title: A framework for techno-economic and environmental sustainability analysis by risk assessment for conceptual process evaluation

Author: Carina L. Gargalo Ana Carvalho Krist V. Gernaey Gürkan Sin

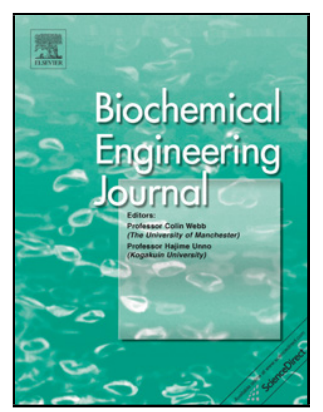

PII: S1369-703X(16)30160-7

DOI: http://dx.doi.org/doi:10.1016/j.bej.2016.06.007

Reference: BEJ 6487

To appear in: Biochemical Engineering Journal

Received date: $\quad 27-1-2016$

Revised date: 22-5-2016

Accepted date: $\quad$ 6-6-2016

Please cite this article as: Carina L.Gargalo, Ana Carvalho, Krist V.Gernaey, Gürkan Sin, A framework for techno-economic and environmental sustainability analysis by risk assessment for conceptual process evaluation, Biochemical Engineering Journal http://dx.doi.org/10.1016/j.bej.2016.06.007

This is a PDF file of an unedited manuscript that has been accepted for publication. As a service to our customers we are providing this early version of the manuscript. The manuscript will undergo copyediting, typesetting, and review of the resulting proof before it is published in its final form. Please note that during the production process errors may be discovered which could affect the content, and all legal disclaimers that apply to the journal pertain. 


\title{
A framework for techno-economic \& environmental sustainability analysis by risk assessment for conceptual process evaluation
}

Carina L. Gargalo ${ }^{1}$, Ana Carvalho ${ }^{2}$, Krist V. Gernaey ${ }^{1}$ and Gürkan Sin $^{1 *}$

${ }^{1}$ CAPEC-PROCESS Research Center, Department of Chemical and Biochemical Engineering, Technical University of Denmark, DK-2800 Lyngby, Denmark

${ }^{2}$ CEG-IST, Instituto Superior Técnico, Universidade de Lisboa, Portugal

*gsi@kt.dtu.dk

\begin{abstract}
The need to achieve a sustainable process performance has become increasingly important in order to keep a competitive advantage in the global markets. Development of comprehensive and systematic methods to accomplish this goal is the subject of this work. To this end, a multi-level framework for techno-economic and environmental sustainability analysis through risk assessment is proposed for the early-stage design and screening of conceptual process alternatives. The alternatives within the design space are analyzed following the framework's work-flow, which targets the following: (i) quantify the economic risk; (ii) perform the monetary valuation of environmental impact categories under uncertainty; (iii) quantify the potential environmental risk; (iv) measure the alternatives' eco-efficiency identifying possible trade-offs; and, lastly (v) propose a joint risk assessment matrix for the quantitative and qualitative assessment of sustainability at the decision-support level. Through the application of appropriate methods in a hierarchical manner, this tool leads to the identification of the potentially best and more sustainable solutions.
\end{abstract}


Furthermore, the application of the framework is highlighted by screening two conceptual glycerol bioconversion routes to value-added chemicals namely 1,3-propanediol (1,3-PDO) and succinic acid.

Keywords: conceptual process, techno-economic assessment, environmental assessment, uncertainty analysis, glycerol biorefinery

\section{Introduction}

Global concerns about climate change, energy security, exhaustion of fossil resources and its societal impacts, have become important for policy and decision-makers. These facts lead to new challenges for the (bio)chemical and processing industries, which motivate researchers to incorporate sustainability matters into the design of new chemical and biochemical processes. Therefore, the bio-based economy has been seen as a key approach that may meaningfully lead to long term sustainable development, where bio-based chemicals and fuels may play a relevant role that will potentially contribute to the replacement of oil-based resources [1]. Due to the multidimensional nature of sustainability, the design and analysis of sustainable biorefineries is built on multi-criteria and multi-objective decision making procedures, leading to complex problems. The complexities arise not only from the multi-evaluation techniques to be chosen, but also from the significant amount of input data required to perform the sustainability analysis, data which may originate from different sources, with different degrees of uncertainty [2], [3]. The comparison and screening of potential processes at the conceptual design phase of biorefineries is marked by assumptions, hypotheses and simplifications that need to be made in order to represent the complexity of the problem. Therefore, it implies that during the first stages of biorefinery design and development, since real data is often incomplete or not available, there are several alternative technologies, feedstocks and products, generating a great number of potential processing pathways. 
Hence, there is a need for screening and gathering the most appropriate processing networks regarding economics, environmental constraints and overall sustainability. Consequently, uncertainty on the techno-economic parameters/criteria is expected, and needs to be appropriately dealt with [4].

Furthermore, uncertainty in environmental assessment originates from, among others, inaccurate measurements, lack of data and erroneous model assumptions (inaccurate or unreliable assumptions when the modeler has to make decisions under limited or no data availability) [5]. For the sake of simplicity, data uncertainty is divided into lack of data (data gaps or lack of representative data for the studied system) and data inaccuracy [6].

There are several proposed approaches on how to deal with error propagation, such as, fuzzy logic [7], Gaussian formulas [8], [9] and the Monte Carlo technique, as the most commonly used methods for propagation of parameter uncertainty [10]-[14].

Despite the considerable work being done on the development of initiatives to include propagation of uncertainty in environmental assessments [10], [15], the results are usually reported based on deterministic data [10], [16].

Regarding deterministic models, a good decision is based on the outcome on its own. However, in very few decision-making circumstances, perfect/complete information is available for the decision maker (i.e. all the needed data with sufficient accuracy is present). The majority of decisions are made in spite of uncertainty, where probability comes into the process as a representation of complete knowledge [17]. Hence, probability assessment stands out as quantification of uncertainty and as an important tool for both communicating uncertainty and managing it.

Furthermore, under uncertainty conditions, the decision maker is concerned not only with the value of the outcome but also with the extent of risk that each decision carries. Quantified based on the uncertainty for which the probability distribution is known (or projected), risk is equal to the sum of 
probabilities of outcome(s) (likelihood of occurrence) times the projected loss as a consequence of the outcome(s).

Consequently, risk-based decision-making provides information in an organized structure about the possibility of one or more unwanted outcomes to occur and its potential economic loss. This information helps managers towards more informed and realistic choices regarding project feasibility.

Examples of studies/methodologies used to compare alternatives based on predefined criteria/indicators and their integration are: Azapagic et al. (2006) [18], where a methodology is presented to guide the user through different design stages for the integration of technical, economic, environmental and social criteria; Sacramento-Rivero (2012) [19] propose a performance assessment methodology applicable to biorefineries where a sustainability scale is used based on an absolute reference, and normalized for sustainability indicators applicable to biorefineries; Martinez-Hernandez et al. (2013) [20] introduce a tool that result from the combination of the value analysis method for the evaluation of economic potential with environmental footprinting for impact analysis; Sacramento-Rivero et al. (2015) [21] illustrate the integration of sustainability indicators for the design of a potentially sustainable switchgrass biorefinery; and, Sanchez et al. $(2014,2016)$ [22], [23] use a framework that aims at the calculation of the overall impacts, for both economic and environmental domains and provide information that could be used to improve the sustainability of the processes under analysis.

Another approach is to identify the optimal solution among different alternatives based on a given objective function. Authors in [24]-[26] present a literature review on programming techniques explored to identify the optimal alternative through single or multi-objective optimization.

Notwithstanding that many studies focused on the economic and environmental domains of sustainability, it should be noted that the majority of these studies measure sustainable performance 
solely under deterministic conditions, where uncertainty and the associated risk a decision carries, is disregarded. Accordingly, as far as we are aware, no other studies have proposed a combined techno-economic and environmental risk quantification matrix for sustainability assessment and decision-making. Therefore, this work proposes a step-by-step framework whose purpose is to identify the best potential alternative(s) that would sustainably create value with the least potential risk of economic and environmental impact. This is achieved by systematically integrating uncertainty and sustainability analysis into a risk assessment framework. The framework aims to stablish a holistic view regarding the following: (i) estimation of the deterministic economic and environmental metrics; (ii) use of Monte Carlo technique for propagation of uncertainties to the environmental and economic indicators; (iii) quantification of the economic risk; (iv) monetary valuation of environmental impact categories under uncertainty; (v) quantification of the potential environmental risk; (vi) use of the sustainability risk matrix as a visual tool for quantitative and qualitative analysis for decision-making. Moreover, performing qualitative analysis by making use of the sustainability risk assessment matrix (as a visual aid tool), is a valuable advantage/benefit of the framework which facilitates exchange of information among experts and non-experts.

The remaining sections of this article are structured as follows: (i) the framework section introduces a step-by-step explanation (user guide) of how to use the quantification of risk as an integrating tool decision-making; then (ii) the framework is highlighted through its application to a relevant case study, the glycerol valorization to value added products namely 1,3-PDO and succinic acid; and finally, (iii) conclusions from the work are presented.

\section{Decision-support framework for techno-economic \& environmental sustainability analysis by risk assessment for conceptual process evaluation}


The proposed framework is based on the combination of two previously presented methodologies, where a methodology for environmental assessment under uncertainty was proposed [27] and an algorithm for the techno-economic assessment under uncertainty was presented [28]. These two methodologies are now combined, and the analysis is taken a step further by incorporating a quantitative and qualitative sustainability analysis by risk assessment. Therefore, the framework's main goal is to systematically, at an early stage of process design, collect, evaluate and screen the alternatives within the design space, through a comprehensive sustainability analysis by risk assessment.

As presented in Figure 1, the framework work-flow is composed of six steps: (1) problem definition; (2) data collection and management; (3A) deterministic techno-economic analysis; (3B) deterministic environmental analysis; (4) Monte Carlo technique for uncertainty analysis; (5) economic and environmental risk quantification; and, (6) risk assessment and decision-making.

\section{Step 1: Problem definition}

In this step, as shown in Figure 1, the user (decision-maker) has to define if the problem is to be solved through a process- or product-oriented approach.

A product-oriented approach is recommended when, the aim is to produce a specific product (or a set of products) and the decision-maker wants to evaluate several paths for its production. This is the case of a retrofit problem, where one wants to change or adapt the existing plant in order to have more production routes and/or to have different sources of feedstock being converted in the plant. Whereas a process-oriented approach should be used when the user is aiming to evaluate a number of paths to synthetize a set of products from a certain (already selected) raw material and, therefore, the question is the selection of product portfolio. Then it would result in a completely new plant. Based on this, the system boundaries and the functional unit (FU) should be defined. Hence, the 
framework application would assist the decision-maker to systematically draw the analysis boundaries and define the functional unit (FU).

\section{Step 2: Data collection \& management}

The Step 2, as shown in Figure 1, targets to establish the design space from which the potential best alternative will be identified. Hence, all the data required for the subsequent steps is gathered into a multidimensional matrix (database) of process technologies, storing all the relevant data required to perform the subsequent steps, representing the alternatives within the boundaries. The database includes: (i) possible processing networks; (ii) the parameters needed to solve the generic block model equations (e.g. stoichiometry, conversion, mixing, product separation, waste separation) [29][30]; and, (iii) techno-economic data (such as prices of raw materials and products and capital and operating costs). The data needed can be obtained by literature review, from real plant data and/or process simulation. It is important to note that, when considering bioprocesses, it is usual the case that real data and literature data are unavailable or incomplete, and therefore data validation and/or consolidation together with process simulation is often required [27].

Lastly, the generic block model equations (please see [29][30] for more details) are solved using a mathematical solver, where the processes are simulated in order to obtain the mass and energy balances, fulfilling fundamental data requirements for the next steps.

\section{Step 3A: Deterministic techno-economic analysis}

The techno-assessment under uncertainties workflow is composed of two sub-steps as shown in Figure 1.

\section{Step 3A.1: Economic model initialization}

To make an investment decision, the forecasted profit from an investment must be assessed relative to some quantitative profitability measurements with regards to the investment needed to generate 
that profit. As discussed in earlier work [28], for the project evaluation, the economic model used is the discounted cash-flow rate of return (DCFROR) which considers the time value of money. By setting a target discount rate (aka internal rate of return), this model enables the calculation of the net present value (NPV), and the minimum selling price. Please see supplementary material, section B, for detailed information on the methodological assumptions, model equations and input parameters.

NPV is used to assess the economic viability of the projects within the design space, which is then used to comprehensively compare the process alternatives. This method is especially recommended when uncertainties are present and thus risk is a challenge [31]. The discount rate is usually set by the investors, and it reflects the minimum rate of return that the company has decided to accept for a new investment, which is in fact a way for the company to adjust to the built-in risk of a project.

In order to generate the base case solutions (baseline) and to identify the first ranking of solutions, the DCFROR is initialized. To this end, the problem is formulated and solved by maximizing $N P V$ for each of the processing networks using the nominal input parameters, such as prices of product(s) and raw material(s), capital and operating costs (data previously collected).

\section{Step 3A.2: Identification of input parameters with high impact on the model}

To identify which external input parameters have higher influence in the economic model selected, a deterministic sensitivity analysis is performed. Therefore, the $N P V$ is re-calculated by changing one input parameter at a time over its expected range of variability. The sensitivity analysis will reflect how sensitive the model is to each parameter, providing an insight on the parameters degree of risk involved in foreseeing the economic performance of the project. Therefore, these parameters are studied further in order to analyze not only the degree of uncertainty that they carry into the model but also how to propagate it and then interpret the results. 


\section{Step 3B: Deterministic environmental analysis}

This step targets to assess the deterministic environmental impact of the processing networks within the design space by calculating their corresponding categories of impact $\left(S_{c}\right)$, as discussed in in [27]. Important to note, is that the $S_{c}$ are pre-determined by the selection of the Life Cycle Impact Assessment (LCIA) characterization method according to ISO 14040 standards. Thus, for each category, all substances contributing to it are converted and summed up (see Eq. 1), in order to be represented by one indicator.

$\mathrm{S}_{c}=\sum_{i} \mathrm{CF}_{i, c} \times \mathrm{F}_{i} \quad[32][33]$

Where $\mathrm{CF}_{\mathrm{i}, \mathrm{c}}$ and $\mathrm{F}_{\mathrm{i}}$, correspond to the science-based characterization factors for each category of impact and the flux for each component $i$ in the system, respectively.

\section{Step 4: Monte Carlo technique}

This step of the framework aims to characterize and propagate the sources of uncertainty within the techno-economic and environmental analysis. To that purpose, the Monte Carlo technique has been applied.

\section{Step 4.1. Characterization of uncertainty}

As mentioned above, concerning the techno-economic assessment, the most relevant sources of uncertainties are identified by the sensitivity analysis performed in Step 3A.2. The identified sources of uncertainty are characterized by using appropriate statistical distribution functions.

The distribution function portraying the behavior of the uncertainty sources can be obtained from (i) historical data if available (e.g. feedstock and product prices) and, when there is no data available, using (ii) expert review/literature survey assuming a uniform distribution [34]. The term expert review refers to information on typical ranges of variation that can be 
used as first estimates, obtained from published sources and engineering textbooks such as Peters et al. (2003) [35] or Towler \& Sinnott (2013) [36]. Therefore, we are able to evaluate the project's performance under uncertainty where worst case scenarios are also depicted. However, the framework is systematic and flexible, and the input data, namely, uncertainty distributions, can be added or modified according to the updated information the user may have at his/her disposal.

As an example, historical data on the raw materials and products market prices are collected and fitted through appropriate distribution functions after analyzing their behavior over the years.

Regarding the environmental assessment, this work focuses on dealing with parameter uncertainty carried by the characterization factors $\left(\mathrm{CF}_{i, c}\right)$ used in Step 3B for the calculation of impact categories. Even though providing significant information for relative comparisons, since $\mathrm{CF}_{i, c}$ are based on simplifications of more complex models, they are not fully trustworthy for absolute comparisons because they carry substantial uncertainty. Hence, for the characterisation of uncertainties in $\mathrm{CF}_{i, c}$, the expert review method was used, a commonly used approach for uncertainty analysis in engineering studies [34], [37]. Thus, three classes of uncertainties for CFs were defined: the class 1 uncertainty refers to $25 \%$ variation, the class 2 refers to $50 \%$ variation, and the class 3 refers to $75 \%$ variation around the reported (mean) values of $C F s$. The mean value of $C F_{i, c}$ is collected from available databases. Finally, it was assumed that the uncertainty in $C F_{i, c}$ follows a uniform distribution, where the same procedure is performed for all input components in the system within the defined boundaries.

\section{$\underline{\text { Step 4.2. Latin Hypercube Sampling \& Monte Carlo simulations }}$}

The Latin Hypercube Sampling $(L H S)$ is used to sample from the parameter space [37] defined in the previous step, where the user needs to, a priori, specify the total sample number, $N$. After the 
sampling, one obtains a sampling matrix with $N$ rows and $p$ columns, where $N$ is the total number of samples and $p$ refers to the number of uncertain parameters for which the sampling is performed.

After LHS, both economic and environmental model equations, respectively describing the calculation of $N P V$ and $S_{c}$, are evaluated/solved using parameter values from the sampling matrix (usually called Monte Carlo simulations). Therefore, it leads to $N$ solutions for each outcome, which lead to distributions of the model output values (i.e. $N P V$ and $S_{c}$ values) as a result of the propagation of the parameter uncertainties in the input. By incorporating a probabilistic interpretation, the distribution of the outputs will be analyzed by means of empirical cumulative distribution functions $(E C D F)$ and used as input data in the next step.

\section{Step 5: Risk quantification}

As shown in Figure 1, this step is composed of the economic and environmental risk quantification.

\section{Step 5.1: Economic risk quantification}

Risk is estimated as the probability of occurrence of a certain event times the consequence of that same event to happen. In this work, the economic risk ( Risk $\left._{e c o n}\right)$ is quantified by the probability of failing to achieve the targeted $N P V$ ('being lower or equal to') times the magnitude of the consequence of that happening ('loss of profit'). Therefore, the economic risk is given by the probability of the project being non-profitable $(N P V<0)$ times the loss of profit in the event of that happening (consequence). The respective mathematical description is presented in Eq. 2.

Risk $_{\text {econ }}=\sum_{i} \mathrm{P}_{\mathrm{i}} \times \mathrm{M}_{\mathrm{i}}=\sum_{i} \mathrm{P}(\mathrm{NPV} \leq 0) \times\left(N P V_{i}\right)$ Eq. 2

where $i$ is the occurrence of the undesirable event, $P_{i}$ is the probability of that event to occur and $M_{i}$ is the magnitude of the consequence (loss of profit in MM\$)..

\section{$\underline{\text { Step 5.2: Environmental risk quantification }}$}


In this study, the quantification of the environmental risk $\left(\right.$ Risk $\left._{e n v}\right)$ of a certain alternative reflects the total amount that the decision-maker is willing to pay if the impact categories deviate from their deterministic value due to uncertainty on the CFs. Therefore, the Risk ${ }_{e n v}$ is given by the probability of the category $S_{c}$ being higher than the deterministic value multiplied by the consequence of that event happening. The magnitude of the consequence is estimated based on the monetary difference between the deterministic values and the realization of the conservative sample values (class 3 uncertainty, step 4.1) over the plant's production lifetime.

Graphically, the individual risk incurred for each one of the impact categories $S_{c}$ corresponds to the shaded area in the cumulative distribution function presented in Figure 2. The mathematical formulation is given by Eq. 3 .

$\operatorname{Risk}_{e n v}=\sum_{T}\left(\sum_{c} P\left(S_{c} \geq \operatorname{Det}_{c}\right) \times\left|\operatorname{Det}_{c}-S_{c}\right| \times w_{c}\right)=\sum_{T}\left(\sum_{c}\left[\sum_{i} P\left(C F_{i} \geq \operatorname{Det}_{C F_{i}}\right) \times\left|\operatorname{Det}_{C F_{i}}-C F_{i}\right| \times f_{i}\right] \times w_{c}\right)$

Eq. 3

Where, $S_{c}$ correspond to the realization value of the category of impact $c$ and $\operatorname{Det}_{c}$ correspond to the deterministic value of the category of impact c (obtained previously in step 3B) and $T$ reflects the production lifetime of the processing network under consideration. Lastly, $w_{c}$ represents the monetary valuation factors used to convert midpoint or endpoint categories into a normalized and weighted monetary unit.

Monetary valuation for direct comparison is the practice of converting measures of impacts into monetary units and is used to attribute economic value to non-market goods (to which no market exists). Although advantages of such an approach have been being pointed out by several authors such as [38], and the technique is being applied in cost benefit analysis, up to now monetary valuation has not been widely applied in environmental assessments, or more specifically in Life Cycle Assessment ( $L C A)$. However, it presents great potential for interpretation purposes and 
communication of environmental assessment results, due to the fact that decision-makers at the management level need a rough but clear presentation of results.

A summary of existing approaches for monetary valuation, built-in methods and key features is described in [39]. In this work, the weighting factors methodology selected is one given by ECOVALUE08 [40], since our focus is on midpoint indicators and their well-defined cause-effect relationships between compound fluxes and the indicators to which they contribute to. Table 1 shows the weighting factors provided by ECOVALUE08.

\section{Step 6: Risk assessment \& decision-making}

The main goal of this step is to rank and identify the potentially best alternative(s) regarding economic and environmental aspects through risk assessment for sustainability analysis. Therefore, a joined risk interpretation matrix is set as visual aid to facilitate a quantitative and qualitative interpretation of the quantified risk for decision support at early stage design. To this end, both economic and environmental risk are normalized as follows.

$$
\begin{array}{ll}
R E C_{n, j}=\text { Risk }_{\text {econ-norm }, j}=\frac{\text { Risk }_{e c o n, j}}{\left(\sum_{j} \text { Risk }_{e c o n, j}\right) / J} & \text { Eq. } 3 \\
R E N_{n, j}=\text { Risk }_{e n v-n o r m, j}=\frac{\text { Risk }_{e n v, j}}{\left(\sum_{j} \text { Risk }_{e n v, j}\right) / J} & \text { Eq. } 4
\end{array}
$$

Where $\left(\sum_{j}\right.$ Risk $\left._{e c o n, j}\right)$ and $\left(\sum_{j}\right.$ Risk $\left._{e n v, j}\right)$ represent the sum of economic or environmental risk over the number $J$ of alternatives considered within the design space, respectively.

Figure 3 presents the proposed qualitative matrix for decision-support, where, after normalization, the respective normalized risk position given by the pair $\left(R E C_{n, j}, R E N_{n, j}\right)$, is set up for each alternative. The vertical and horizontal axes display the range of normalized economic risk and environmental risk, respectively. Due to the normalization, the center of both axes corresponds to 1 . 
As proposed by [41], the distances of the products from the diagonal can be translated into differences between the respective eco-efficiency performance.

The visualization of results through the interpretation matrix provides not only a quick decisionmaking tool to select the potentially most sustainable alternative within the design space, but also it is an easy way to communicate results in an easily understandable way. To this end, the matrix is divided into four boxes both for qualitative ('which box does it fall in?') and quantitative interpretation ('higher or lower than 1?'). Therefore, from the qualitative point of view, and in clockwise direction: 'Drop' indicates that the alternatives that fall into this box are not promising and therefore they are recommended to be given up; 'Improve' categorizes the alternatives which have low economic risk, however the environmental risk assessment reflects that the process needs to be improved in order to decrease its environmental burden; 'Potential' presents high prospective to be selected as best alternative since it has low economic risk and low environmental risk; and, finally, 'Re-evaluate' classifies the alternatives that have a potential low environmental risk, but the economic risk is significant. In the latter case, improvements in the process could not only improve the economics but also its environmental assessment.

In order to analyze the products' eco-efficiency, one starts by looking at the distances between the initial positions in the matrix and the diagonal line, the higher the distance to the diagonal line the lower the eco-efficiency. Furthermore, the ratio between the normalized environmental and economic risk $\left(R_{j}\right)$ is estimated for each one of the products as given in Eq. 5. If $R_{j}$ is higher than 1 it means that the normalized environmental risk of the product is higher than the normalized economic risk.

This ratio is used not only to analyze the systems' eco-efficiency but it is also useful to update the products' position in the matrix to an improved position, which has a balance between the 
environmental and economic risk, i.e. it is located on the diagonal line. Thus, it allows a quick visualization of possible trade-offs when selecting a certain alternative.

$R_{j}=\frac{R E N_{n, j}}{R E C_{n, j}}$

The improved position is given by the pair $\left(R E C_{n, j}^{\prime}, R E N_{n, j}^{\prime}\right)$ inspired by the procedure proposed in [41], which is based on the theorem of Pythagoras and on the cathetus theorem.

Therefore, based on the sustainability analysis performed through the joined risk assessment, the user will be able to quickly assess which alternative stands out as potentially more sustainable, and also identify possible trade-offs.

\section{Case study results}

The increased environmental concerns and the consequent demand for less harmful transportation fuels have led to a growing interest in biofuels. Biodiesel, one promising alternative among the known renewable energy sources, has been receiving greater interest than before. Therefore, since its production capacity has increased over the last years, so did the amount of residues (crude glycerol and pies) generated during its manufacture.

Since the crude glycerol is produced in stoichiometric proportions to biodiesel $(10 \mathrm{~kg}$ biodiesel to 1 $\mathrm{kg}$ of glycerol), the surplus of crude glycerol created in the biodiesel industry is leading to a drop in glycerol prices and, hence, the glycerol is now considered a waste instead of a coproduct [42]. Therefore, the growth of biorefineries based on the valorization of glycerol is anticipated to help the biodiesel companies and their economy, by cutting costs related to the discharge of residues and increasing production of value-added chemicals, possibly acting as a driving force to increase global sustainability of the biodiesel industry [43], [44].

Hence, the framework is applied in order to analyze and identify the most environmentally friendly designs under uncertainty among the proposed glycerol bioconversion schemes. 


\section{Step 1: Problem definition}

The framework is highlighted by the application to the glycerol valorization, where the aim is to identify the best alternative to add value to crude glycerol, by the production of succinic acid or 1,3propanediol as value-added products. Since the goal of the study is to identify the best potential product, the functional unit is the inflow of crude glycerol (1 $\mathrm{kg}$ of glycerol). The system boundaries are defined following a gate-to-gate approach as described in Figure 4, which includes the manufacturing process and the utilities scheme.

\section{Step 2: Data collection \& Management}

As mentioned previously, all input data needed to perform the subsequent steps is collected and stored in a multidimensional matrix. The mass and energy balances were estimated based on the input data (please see Table A2, section 2, supplementary material) and following the generic block model equations (e.g. stoichiometry, conversion, mixing, product separation, waste separation) [29][30]. Additionally, the techno-economic data required for Steps 3A and 4, such as nominal market prices of products and raw material(s); and key assumptions for the economic model, are also collected and presented in Table 2 and 3. Regarding the data requirements of the environmental assessment, after selecting the LCIA methods, the characterization factors $(C F s)$ are also collected and stored in the database. In this work the LCIA method selected is the ReCiPe method [45]. It is important to note that, having defined the LCIA method, the indicators and characterization factors are preselected and used in the subsequent steps.

\section{Step 3A: deterministic techno-economic analysis}

\section{Step 3A.1: Economic model initialization}

To generate the base cases conditions and obtain the first ranking of solutions, the problem is solved maximizing the NPV of the processing networks within the design space. To this end, all the input 
data required for the calculation of Eqs. 2 to 9 [28], such as input parameters, have already been collected (e.g. market prices of products and raw materials, see Table 3) or estimated (e.g. fixed and variable operating costs). The summary of key input assumptions used in the economic model is presented in Table 2.

In this work, the fixed and variable operating costs are estimated based on the factorial methodology. Therefore, as starting point, the fixed capital investment (FCI) needs to be estimated. The capital investment was calculated based on dividing the processing routes/pathways into three sections as shown in Figure 5. The capital investment for the purification of crude glycerol was calculated on the basis of data available for a medium-sized biodiesel plant in Europe [50]. It has an input flowrate of 4200 ton glycerol/year $(\sim 525 \mathrm{~kg} / \mathrm{h})$, corresponding to $10 \%(\mathrm{w} / \mathrm{w})$ of the total annual biodiesel production rate $\left(37.85 \times 10^{6} \mathrm{~L}\right)$. A detailed equipment list and their cost can be found in supplementary material. For the remaining process sections, the FCI was estimated based on literature review of all products and scaled to the production rate set by the verified stoichiometry. The purchased equipment costs were then estimated based on the product specific references (base) and adapted to appropriate capacities (plant $X$ ), and the respective costs were updated to year 2014, as presented in Eq. 1. The factorial methodology, as presented in [35] is then applied based on the purchased equipment cost. Table 4 presents the data required for the application of the economic model and the nominal values obtained for NPV and MSP (for the model equations please see supplementary material, section A2, Eqs.1 to 8).

$\operatorname{Cost}_{\mathrm{X}}{ }^{2014}=\left[\right.$ Cost $\left._{\text {base }} \times\left(\frac{\text { Capacity }}{\mathrm{X}}\right)^{n}\right] \times \frac{\mathrm{CEPCI}_{2014}}{\text { CEPacity }_{\text {base }}}$ Eq.1

Where Cost $_{\mathrm{X}}{ }^{2014}$ represents the purchased cost for plant $\mathrm{X}$ calculated from the Cost ${ }_{\text {base }}$ of a similar plant with similar functionality; $\mathrm{CEPCI}_{2014}$ and $\mathrm{CEPCI}_{\text {base }}$ represent the Chemical Engineering's 
Plant Cost Index (see Supplementary material, Figure A1) for 2014 and for the year base (reference year for each case), respectively.

Studies on glycerol conversion have been reported along the years such as [51]-[55], among others. Vlysidis et al. [52] analyzed the coproduction of succinic acid for the glycerol valorization; where the total production cost (TPC) obtained is approximately $4.37 \mathrm{M} \$ / \mathrm{y}$, updated for the capacity difference, the use of the same inlet of crude glycerol as raw material and updating it with the euro/dollar exchange rate from mid-2014 (reference year as shown in Table 2). As presented in Table 4, the TPC obtained in this work for the production of succinic acid is approximately 3.86 $\mathrm{M} \$ / \mathrm{y}$, being within a range of variation of less than $12 \%$ from the TPC reported in Vlysidis et al. [52]. Moreover, the TPC for 1,3-PDO obtained in this work is within $15 \%$ of variation from the reported value of TPC of 1,3-PDO presented in Posada et al. [55] (3.49 M\$/y), which, for the sake of comparison, has also been updated accordingly. It is important to note that, considering that the above are deterministic assessments at early stage design, differences are expected not only due to different methodological choices but also due to shortcomings related to the possible lack of awareness of market fluctuations and technical variabilities.

\section{Step 3A.2: Identification of input parameters with high impact on the model}

The investment and cash-flows are firstly calculated for the baseline conditions, and then the NPV is re-estimated by changing one variable at a time over the expected range of variability of key economic factors (see Table 5). This will express how sensitive the DCFR model is, to variations in the input information. From Figure 5, it was concluded that (i) external input parameters such as feedstock price, product price, sales volume and fixed capital investment have a relatively high impact on the projected economic performance; and, (ii) the discount rate also has a significant 
impact on the economic model. Thus, in this study the above-mentioned sources of uncertainty are taken into account and analyzed further.

\section{Step 4: Monte Carlo technique}

\section{Step 4.1: characterization of sources of uncertainty}

As mentioned earlier in Step 3A.2, the external sources of uncertainty identified by the sensitivity analysis are now characterized using appropriate statistical distribution functions.

Therefore, for further analysis, the scenario to be analyzed was set-up based on (i) historical data on the raw materials and products market prices described through appropriate probability distribution functions; (ii) considering variability of the fixed capital investment over its typical range of variation; and, (iii) considering the variation of the sales volume by allowing it to vary in its probable range. Concerning the uncertainty in the LCIA, as discussed above the $\mathrm{CF}_{i, c}$ were identified as carrying substantial uncertainty. The input uncertainty domain is defined by the expert review method and assuming a uniform distribution as mentioned above (description of step 4.1).

\section{$\underline{\text { Step 4.2: LHS \& Monte Carlo simulations }}$}

Through Latin hypercube sampling with correlation structure/control [34], [37] 500 future scenarios (realizations of uncertainty) were generated for each of the input parameters from the input uncertainty domain.

Therefore, the output of this step is composed by two $N x M$ matrices, corresponding to input uncertainty identified in the techno-economic assessment and in the LCIA, where $N$ represents the number of samples obtained with $L H S$ and $M$ represents the uncertain parameters.

In order to identify the optimal processing networks, the optimization problem was formulated and solved, which led to 500 optimal solutions (Monte Carlo simulations) that are mapped and 
statistically analyzed. The frequency of selection of succinic acid and 1,3-propanediol are 0.84 and 0.16 , respectively (also presented in Table 8).

\section{Step 5: Risk quantification}

\section{$\underline{\text { Step 5.1: Economic risk quantification }}$}

In this study, as mentioned earlier, the economic risk is quantified by following Eq. 2.

As identified in step 3A.2, the discount rate is an important source of uncertainty mostly set by management choices. In this case study, the project to be selected represents the implementation of a new technology, and therefore the project discount rate (IRR) is adjusted to offset risk and attract investors. It is, therefore, considered to be somewhere between medium to high, and so the minimum acceptable rate of return is set to be $24 \%$. Thus, to represent the effect of the company choices with respect to the level of IRR used, the NPV is estimated considering both $I R R$ of $10 \%$ and 24\% [35]. In Figure 5, two curves are depicted in red and blue, representing $N P V$ obtained at $10 \%$ and $24 \%$ internal rate of return respectively, where the calculation of risk is equivalent to the shaded area in the cumulative distribution function for $N P V$ as shown in Figure 5. A summary of the economic risk results is presented in Table 4.

Table 6 presents a summary of results and Figure 5 graphically presents the results obtained for the products under consideration, where we analyze the probability of NPV being lower than zero times the consequence of that event occurring. In other words, the economic risk will reflect the probability of the biorefinery concept under study to be non-profitable (non-viable) which corresponds to a NPV lower than zero. To this end, the crude glycerol valorization through the production of succinic acid is potentially the best investment alternative since it has a lower risk of being non-profitable than 1,3-PDO, representing a potential profit loss of 41 and $63 \mathrm{M} \$$ at a discount rate of $10 \%$, respectively. Although the lower capital investment required leads to a 
quantified economic risk of $20 \mathrm{M}$, selling the purified glycerol as the only product ("do nothing" alternative) presents a probability of NPV being lower than zero of 1 , and, therefore, is nonprofitable for the full realization of uncertainty. Also, it is important to note that, due to the fact that the market for refined/pharmaceutical grade of glycerol is nearly saturated, it is faced with global oversupply, and therefore there is a limited demand for purified glycerol [59], [60]. This fact was not taken into account in the estimation of risk for the "do nothing alternative", it was then considered that all crude glycerol available is refined and sold. However, as above discussed, the goal of the framework's application to the case study is from a process point of view; it then assists a chemical company in further developing projects and performing feasibility assessments. Therefore, the application of the framework to this case study enables the project developers to identify the best potential alternative in the design space to sustainably add value to the glycerol side-stream.

\section{$\underline{\text { Step 5.2: Environmental risk quantification }}$}

The environmental risk was quantified following Eq. 3, and using the monetary valuation factors in Table 1, where the built-in risk of each category Risk ${ }_{e n v, c}$ is given by the probability of the category $S_{c}$ being higher than the deterministic value multiplied by the consequence of that event happening. The empirical cumulative distribution function (ECDF) obtained as output of Step 4.2, and built based on the realization of conservative sample values (class 3 uncertainty, step 4.1), is used in order to read the cumulative probability needed for the estimation of risk for each category $S_{c .}$. Then, the consequence is calculated based on the monetary difference between the deterministic values of each category and the realization of the conservative sample values over the plant's production lifetime.

In this case study, the plant lifetime is taken to be consistent with the economic assumption lifetime of 30 years (Table 2). However, since the first three years correspond to the plant construction (no 
production), 27 years is the entire period where the plant is operating and thus this is the time over which the environmental risk is quantified. The quantified environmental risk of 1,3-PDO and succinic acid is 47.7 and 53.9 M\$/lifetime, respectively (shown also in Table 5). Therefore, based only on environmental risk and performance one can see that the production of 1,3-PDO stands out as being slightly better than the production of succinic acid.

\section{Step 6: Combined risk assessment \& decision-making}

In order to assess the alternatives within the design space and identify the potentially best alternative, the proposed combined risk assessment matrix is used for decision-support.

The position of both products in the matrix $\left(R E C_{n, j}, R E N_{n, j}\right)$ is obtained by using the Eqs. 3 and 4; the results are summarized and presented in Table 5 and shown in Figure 6.

In this case study as shown in Figure 6, we can see that the production of 1,3-propanediol is located in the 'Re-evaluate' box and the succinic acid production is located in the 'Improve' box. It is then clear that the potentially best alternative to be chosen for further investigation is the succinic acid production. However, the process needs to be improved in order to decrease its environmental burden and hence decrease its potential environmental risk. This is also highlighted by the succinic acid alternative's $\mathrm{R}$ factor (see Table 5), which being higher than 1 shows that the normalized environmental risk has a greater impact that the normalized economic risk.

Figure 7 shows in detail the slight difference on the eco-efficiency of succinic acid over 1,3-PDO, where succinic acid presents itself more advantageously since the environmental benefit given by 1,3-PDO is evaluated not to be worth its additional economic risk.

Moreover, the $R_{j}$ and the improved positions $\left(R E C^{\prime}{ }_{n, j}, R E N^{\prime}{ }_{n, j}\right)$ were estimated and shown in Table

5. The improved positions $\left(R E C^{\prime}{ }_{n, j}, R E N_{n, j}^{\prime}\right)$ represented in Figure 8, aim at establishing a balance 
between the economic and environmental risk, and therefore following the approach presented in the framework description, they are set upon the diagonal line. Finally, after analyzing the risk contributions of both products, one can deduce that choosing succinic acid is a safer choice, which potentially leads to a more sustainable solution for the glycerol valorization. This is also supported by existing commercial production plants such as: Reverdia producing $10 \mathrm{kton} / \mathrm{y}$ of Biosuccinium from renewable carbon sources (fermentable sugars) in Italy, since 2012 [61]; Succinity, a joint venture between Corbion Purac and BASF built in 2013, also having a 10kton/y working plant in Spain since 2013; and, Myriant and Bioamber, with the same range of installed capacities, operating in Canada and North America, respectively [62]. Succinic acid (and its salts) has been projected to be one of the future platform chemicals obtainable from renewable resources and has noteworthy potential as building block; for the production of biopolymers [63], to be used in food, pharmaceutical and cosmetic activities as well as its transformation into solvents and other existing petro-based chemicals [64].

Furthermore, it is important to note that, the uncertainty analysis and risk assessment results presented here depend on the framing of the problem which includes (i) sources of uncertainty identified, (ii) the uncertainty ranges defined (based on historical price range, internal company experiences, process expert/engineering insights, textbooks, etc). Therefore these results should be interpreted within that framing. However since the methodology is flexible, the uncertainty and risk analysis can be iterated as the user has more refined/updated information on sources/magnitude of uncertainties in the project development.

\section{Conclusions:}


A flexible and systematic framework for sustainability analysis incorporating techno-economic and environmental risk assessment is proposed as a decision-support tool to help rank the alternatives within the design space and identify the best potential conceptual process. To this end, the framework leads the user to actively: (i) identify techno-economic sources of uncertainty and, through uncertainty propagation, (ii) quantify the economic risk; (iii) perform the monetary valuation of environmental impact categories under uncertainty; (iv) quantify the potential environmental risk; (v) measure the alternatives' eco-efficiency identifying possible trade-offs; and, lastly (vi) use a sustainability risk assessment matrix for quantitative and qualitative assessment at the decision-support level also enabling information transfer to non-experts. The benefit given by the combined risk assessment matrix is a quick graphic analysis of all products within the design space, therefore after estimating the normalized position the user is able to visually identify the optimal solution.

Enterprises are under increasing pressure to assess/ evaluate environmental, social, and economic impacts of the projects they evaluate. Thus, the proposed framework provides a meaningful measure of sustainability, being a useful and flexible way for companies to evaluate their processes/products from a quantitative and qualitative stand-point. In this way, the proposed methodology is providing the user with a useful and flexible tool for the decision-making support at the conceptual phase, which allows a quick assessment of results to facilitate decisions concerning which products to select or reject for further process development efforts.

\section{Acknowledgements}


We thank the Reneseng Project, Marie Curie Initial Networks (ITN), Grant agreement 607415 for the financial support.

\section{References:}

[1] J. J. Bozell and G. R. Petersen, "Cutting-edge research for a greener sustainable future Technology development for the production of biobased products from biorefinery carbohydrates — the US Department of Energy' s 'Top 10' revisited," Green Chem., vol. 12, no. 4, 2010.

[2] C. L. Gargalo, K. V. Gernaey, and G. Sin, "Sustainable Process Design under uncertainty analysis: targeting environmental indicators," Comput. Aided Chem. Eng., vol. 37, no. 01/2015, pp. 2579-2584, 2015.

[3] A. E. Björklund, "Survey of Approaches to Improve Reliability in LCA," Int. J. Life Cycle Assess., vol. 7, no. 2, pp. 64-72, 2002.

[4] R. Turton, Analysis, synthesis and design of chemical processes. Prentice Hall, 2009.

[5] R. Heijungs and M. a J. Huijbregts, "A review of approaches to treat uncertainty in LCA," iEMSs 2004 Int. Congr., p. 8, 2004.

[6] M. A. J. Huijbregts, G. Norris, R. Bretz, A. Ciroth, B. Maurice, B. Von Bahr, B. Weidema, and A. S. H. De Beaufort, "Framework for Modelling Data Uncertainty in Life Cycle Inventories," Int. J. Life Cycle Assess., vol. 6, no. 3, pp. 127-132, 2001.

[7] E. Benetto, C. Dujet, and P. Rousseaux, "Integrating fuzzy multicriteria analysis and uncertainty evaluation in life cycle assessment," Environ. Model. Softw., vol. 23, no. 12, pp. 1461-1467, Dec. 2008.

[8] R. Heijungs, "Identification of key issues for further investigation in improving the reliability of life-cycle assessments," J. Clean. Prod., vol. 4, no. 3-4, pp. 159-166, Jan. 1996.

[9] R. Heijungs, S. Suh, and R. Kleijn, "Numerical Approaches to Life Cycle Interpretation The case of the Ecoinvent'96 database (10 pp)," Int. J. Life Cycle Assess., vol. 10, no. 2, pp. 103-112, Jun. 2004.

[10] M. a J. Huijbregts, "Application of uncertainty and variability in LCA. Part I: A general framework for the analysis of uncertainty and variability in life cycle assessment," Int. J. Life Cycle Assess., vol. 3, no. 5, pp. 273-280, 1998.

[11] K. G. Canter, D. J. Kennedy, D. C. Montgomery, J. B. Keats, and W. M. Carlyle, "Screening stochastic Life Cycle assessment inventory models," Int. J. Life Cycle Assess., vol. 7, no. 1, pp. 18-26, Jan. 2002.

[12] G. Geisler, S. Hellweg, and K. Hungerbühler, "Uncertainty Analysis in Life Cycle Assessment (LCA): Case Study on Plant-Protection Products and Implications for Decision Making," Int. J. Life Cycle Assess., vol. 10, no. 3, pp. 184-192, 2005.

[13] D. McCleese, "Using Monte Carlo simulation in life cycle assessment for electric and internal combustion vehicles," Int. J. Life Cycle Assess., vol. 7, no. 4, pp. 230 - 236, 2002.

[14] G. W. Sonnemann, M. Schuhmacher, and F. Castells, "Uncertainty assessment by a Monte 
Carlo simulation in a life cycle inventory of electricity produced by a waste incinerator," $J$. Clean. Prod., vol. 11, no. 3, pp. 279-292, May 2003.

[15] A. Ciroth, G. Fleischer, and J. Steinbach, "Uncertainty calculation in life cycle assessments," Int. J. Life Cycle Assess., vol. 9, no. 4, pp. 216-226, Jul. 2004.

[16] M. a J. Huijbregts, W. Gilijamse, A. M. J. Ragas, and L. Reijnders, "Evaluating uncertainty in environmental life-cycle assessment. A case study comparing two insulation options for a Dutch one-family dwelling," Environ. Sci. Technol., vol. 37, no. 11, pp. 2600-2608, 2003.

[17] C. Leake and A. L. Golub, "Decision Analysis: An Integrated Approach.," J. Oper. Res. Soc., vol. 49, no. 2, p. 181, Feb. 1998.

[18] A. Azapagic, A. Millington, and A. Collett, "A Methodology for Integrating Sustainability Considerations into Process Design," Chem. Eng. Res. Des., vol. 84, no. 6, pp. 439-452, Jun. 2006.

[19] J. C. Sacramento-Rivero, "A methodology for evaluating the sustainability of biorefineries: framework and indicators," Biofuels, Bioprod. Biorefining, vol. 6, no. 1, pp. 32-44, Jan. 2012.

[20] E. Martinez-Hernandez, G. Campbell, and J. Sadhukhan, "Economic value and environmental impact (EVEI) analysis of biorefinery systems," Chem. Eng. Res. Des., vol. 91, no. 8, pp. 1418-1426, Aug. 2013.

[21] J. C. Sacramento-Rivero, F. Navarro-Pineda, and L. E. Vilchiz-Bravo, "Evaluating the sustainability of biorefineries at the conceptual design stage," Chem. Eng. Res. Des., vol. 107, pp. 167-180, Mar. 2016.

[22] A. Sanchez, G. Magaña, M. I. Partida, and S. Sanchez, "Bi-dimensional sustainability analysis of a multi-feed biorefinery design for biofuels co-production from lignocellulosic residues and agro-industrial wastes," Chem. Eng. Res. Des., vol. 7, pp. 195-217, 2015.

[23] A. Sanchez, G. Magaña, D. Gomez, M. Solís, and R. Banares-Alcantara, "Bidimensional sustainability analysis of lignocellulosic ethanol production processes. Method and case study,” Biofuels, Bioprod. Biorefining, vol. 8, no. 5, pp. 670-685, Sep. 2014.

[24] F. You, L. Tao, D. J. Graziano, and S. W. Snyder, "Optimal design of sustainable cellulosic biofuel supply chains: Multiobjective optimization coupled with life cycle assessment and input-output analysis," AIChE J., vol. 58, no. 4, pp. 1157-1180, Apr. 2012.

[25] D. Yue, M. A. Kim, and F. You, "Design of Sustainable Product Systems and Supply Chains with Life Cycle Optimization Based on Functional Unit: General Modeling Framework, Mixed-Integer Nonlinear Programming Algorithms and Case Study on Hydrocarbon Biofuels BT - ACS Sustainable Chemistr," Sustain. Chem. Eng., pp. 1-15, 2013.

[26] J. Gong and F. You, "Sustainable design and synthesis of energy systems," Curr. Opin. Chem. Eng., vol. 10, pp. 77-86, Nov. 2015.

[27] C. L. Gargalo, P. Cheali, J. A. Posada, A. Carvalho, K. V. Gernaey, and G. Sin, "Assessing the environmental sustainability of early stage design for bioprocesses under uncertainties: An analysis of glycerol bioconversion," Submitt. to ACS Sustain. Chem. Eng., 2015.

[28] C. L. Gargalo, P. Cheali, J. A. Posada, K. V. Gernaey, and G. Sin, "Economic risk assessment of early-stage designs for glycerol valorization in biorefinery concepts," Accept. Publ. Ind. Eng. Chem. Res., 2015.

[29] A. Quaglia, C. Gargalo, G. Sin, and R. Gani, "Systematic network synthesis and design: 
problem formulation, superstructure generation, data management and solution," Comput. Chem. Eng., vol. 72, p. 68, 2015.

[30] P. Cheali, A. Quaglia, K. V Gernaey, and G. Sin, "Effect of Market Price Uncertainties on the Design of Optimal Biore fi nery Systems - A Systematic Approach," Ind. Eng. Chem. Res., vol. 53, no. 14, pp. 6021-6032, 2014.

[31] W. Short, D. J. Packey, and T. Holt, A manual for the economic evaluation of energy efficiency and renewavble energy technologies. Colorado: National Renewable Energy Laboratory, US Department of Energy, 1995.

[32] European Commission - Joint Research Centre - Institute for Environment and Sustainability, International Reference Life Cycle Data System (ILCD) Handbook-General guide for Life Cycle Assessment -Detailed guidance, First Edit. EUR 24708 EN. Luxembourg: Publications Office of the European Union, 2010.

[33] M. A. Curran, "Life cycle assessment: principles and practice," Cincinnati, Ohio, 2006.

[34] J. C. Helton and F. J. Davis, "Latin hypercube sampling and the propagation of uncertainty in analyses of complex systems," Reliab. Eng. Syst. Saf., vol. 81, no. 1, pp. 23-69, Jul. 2003.

[35] M. S. Peters, K. D. Timmerhaus, and R. E. West, Plant design and economics for chemical engineers. McGraw-Hill, 2003.

[36] G. Towler and R. Sinnott, Chemical Engineering Design: Principles, Practice and Economics of Plant and Process Design, 2nd ed. Elsevier, 2013.

[37] G. Sin, K. V Gernaey, M. B. Neumann, M. C. M. van Loosdrecht, and W. Gujer, "Uncertainty analysis in WWTP model applications: a critical discussion using an example from design.," Water Res., vol. 43, no. 11, pp. 2894-906, Jun. 2009.

[38] S. Ahlroth, "The use of valuation and weighting sets in environmental impact assessment," Resour. Conserv. Recycl., vol. 85, pp. 34-41, 2014.

[39] M. Pizzol, B. Weidema, M. Brandão, and P. Osset, "Monetary valuation in Life Cycle Assessment: a review," J. Clean. Prod., vol. 86, pp. 170-179, Jan. 2015.

[40] S. Ahlroth and G. Finnveden, "Ecovalue08-A new valuation set for environmental systems analysis tools," J. Clean. Prod., vol. 19, no. 17-18, pp. 1994-2003, Nov. 2011.

[41] A. Kicherer, S. Schaltegger, H. Tschochohei, and B. F. Pozo, "Eco-efficiency: Combining life cycle assessment and life cycle costs via normalization," Int. J. Life Cycle Assess., vol. 12, no. 7, pp. 537-543, Dec. 2006.

[42] S. S. Yazdani and R. Gonzalez, "Anaerobic fermentation of glycerol: a path to economic viability for the biofuels industry.," Curr. Opin. Biotechnol., vol. 18, no. 3, pp. 213-9, Jun. 2007.

[43] F. Yang, M. a Hanna, and R. Sun, "Value-added uses for crude glycerol--a byproduct of biodiesel production.," Biotechnol. Biofuels, vol. 5, no. 1, p. 13, Jan. 2012.

[44] J. R. M. Almeida, L. C. L. Fávaro, and B. F. Quirino, "Biodiesel biorefinery: opportunities and challenges for microbial production of fuels and chemicals from glycerol waste.," Biotechnol. Biofuels, vol. 5, no. 1, p. 48, 2012.

[45] "ReCiPe Mid/Endpoint method, version 1.08 December 2012." [Online]. Available: http://www.lcia-recipe.net/characterisation-and-normalisation-factors. [Accessed: 01-Jan2015]. 
[46] D. Humbird, R. Davis, L. Tao, C. Kinchin, D. Hsu, A. Aden, P. Schoen, J. Lukas, B. Olthof, M. Worley, D. Sexton, and D. Dudgeon, "Process Design and Economics for Biochemical Conversion of Lignocellulosic Biomass to Ethanol Process Design and Economics for Biochemical Conversion of Lignocellulosic Biomass to Ethanol," Golden, Colorado 80401, 2011.

[47] ICIS, "ICIS Dashboard Price History - crude glycerol - 25 August 2010 - 25 August 2015."

[48] P. Davies, "Chemical Business Focus - A monthly roundup and analysis of the key factors shaping world chemicals markets," Bio-Materials Inter Mediat. Incl. biobased Chem. biopoly mers their petroche mical Equiv., no. Issue Number 008, 2014.

[49] E. Molel, H. Phillips, and A. Smith, "1 , 3-Propanediol from Crude Glycerol," Pennsylvania, 2015.

[50] M. J. Haas, A. J. McAloon, W. C. Yee, and T. a Foglia, "A process model to estimate biodiesel production costs.," Bioresour. Technol., vol. 97, no. 4, pp. 671-8, Mar. 2006.

[51] John Alexander Posada Duque, "Design and Analysis of Technological Schemes for Glycerol Conversion to Added Value Products," Universidade Nacional de Colombia, 2011.

[52] A. Vlysidis, M. Binns, C. Webb, and C. Theodoropoulos, "A techno-economic analysis of biodiesel biorefineries: Assessment of integrated designs for the co-production of fuels and chemicals," Energy, vol. 36, no. 8, pp. 4671-4683, Aug. 2011.

[53] J. a. Posada, J. M. Naranjo, J. a. López, J. C. Higuita, and C. a. Cardona, "Design and analysis of poly-3-hydroxybutyrate production processes from crude glycerol," Process Biochem., vol. 46, no. 1, pp. 310-317, Jan. 2011.

[54] M. Morales, P. Y. Dapsens, I. Giovinazzo, J. Witte, C. Mondelli, S. Papadokonstantakis, K. Hungerbühler, and J. Pérez-Ramírez, "Environmental and economic assessment of lactic acid production from glycerol using cascade bio- and chemocatalysis," Energy Environ. Sci., vol. 8, no. 2, pp. 558-567, 2015.

[55] J. Posada, C. Cardona, J. Higuita, J. Tamayo, and Y. Pisarenko, "Design and economic analysis of the technological scheme for 1,3-propanediol production from raw glycerol," Theor. Found. Chem. Eng., vol. 47, no. 3, pp. 239-253, Jun. 2013.

[56] P. Christensen and L. R. Dysert, "Cost Estimate Classification System - As Applied in Engineering, Procurement , and Construction for the Process Industries," 2005.

[57] S. a. El-Temtamy and T. S. Gendy, "Economic evaluation and sensitivity analysis of some fuel oil upgrading processes," Egypt. J. Pet., vol. 23, no. 4, pp. 397-407, 2014.

[58] N. Nguyen and Y. Demirel, "Economic analysis of biodiesel and glycerol carbonate production plant by glycerolysis," J. Sustain. Bioenergy Syst., vol. 3, pp. 209-216, 2013.

[59] R. Ciriminna, C. Della Pina, M. Rossi, and M. Pagliaro, "Understanding the glycerol market,” Eur. J. Lipid Sci. Technol., no. August 2015, 2014.

[60] C. a G. Quispe, C. J. R. Coronado, and J. a. Carvalho, "Glycerol: Production, consumption, prices, characterization and new trends in combustion," Renew. Sustain. Energy Rev., vol. 27, pp. 475-493, 2013.

[61] Reverdia, "Biosuccinium ${ }^{\mathrm{TM}}$ Sustainable Succinic Acid: A Green Building Block to Enable Production of Bio-based Specialty Chemicals," 2015. [Online]. Available: http://www.reverdia.com/products/biosuccinium/. 
[62] E4tech (UK), Re-Cord, and Wageningen-UR, "From the Sugar Platform to biofuels and biochemicals - Final Report for the European Comission Directorate-General Energy," London, 2015.

[63] I. Bechthold, K. Bretz, S. Kabasci, R. Kopitzky, and A. Springer, "Succinic acid: A new platform chemical for biobased polymers from renewable resources," Chem. Eng. Technol., vol. 31, no. 5, pp. 647-654, 2008.

[64] E. Scholten, T. Renz, and J. Thomas, "Continuous cultivation approach for fermentative succinic acid production from crude glycerol by Basfia succiniciproducens DD1.," Biotechnol. Lett., vol. 31, no. 12, pp. 1947-51, Dec. 2009.

[65] M. H. Biebl, "Microbial production of 1, 3-propanediol," Appl Microbiol Biotechnol., vol. 52, no. 3, pp. 289-297.

[66] S. Shams Yazdani and R. Gonzalez, "Engineering Escherichia coli for the efficient conversion of glycerol to ethanol and co-products.," Metabolic engineering, vol. 10, no. 6. pp. 340-51, Nov-2008.

[67] S. Y. Ereev and M. K. Patel, "Standardized cost estimation for new technologies ( SCENT ) methodology and tool," J. Bus. Chem., vol. 9, no. 1, 2012.

[68] P. Cheali, K. Gernaey, and G. Sin, "Uncertainties in early-stage capital cost estimation of process design - a case study on biorefinery design," Front. Energy Res., vol. 3, no. 3, 2015.

[69] M. S. Peters and Klaus D. Timmerhaus, Plant Design ans Economics for Chemical Engineers. 1991.

[70] D. Pretreatment, "Process Design and Economics for Biochemical Conversion of Lignocellulosic Biomass to Ethanol Process Design and Economics for Biochemical Conversion of Lignocellulosic Biomass to Ethanol," no. May, 2011.

[71] “Chemical Engineering Plant Cost Index (averaged over year)," Fakultet for naturvitenskap og teknologi - Process Design course, 2011. [Online]. Available: http://www.nt.ntnu.no/users/magnehi/cepci_2011_py.pdf. 


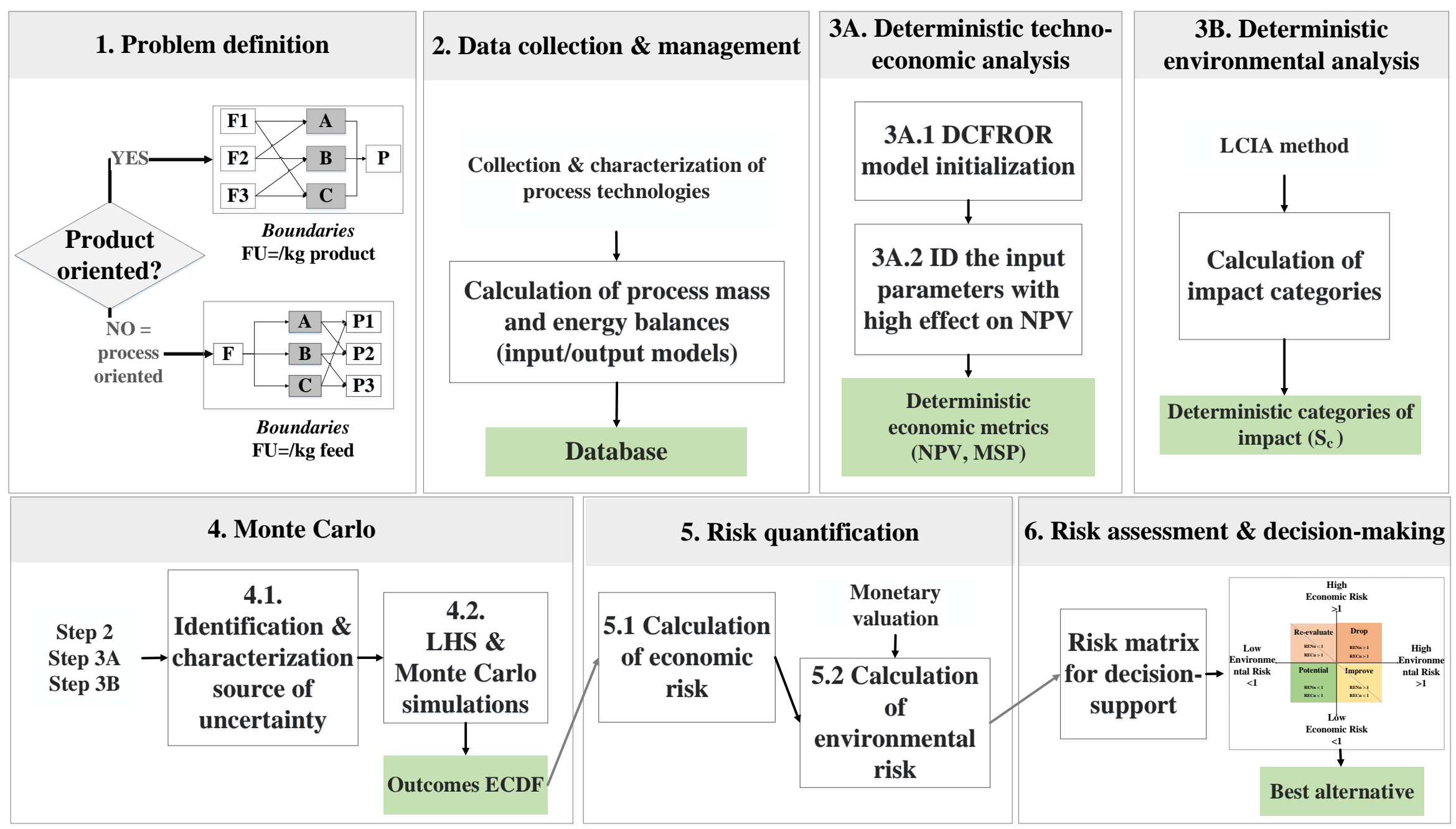

Figure 1: Schematic representation of the framework for sustainability risk assessment at the early-stage of conceptual design and analysis. 


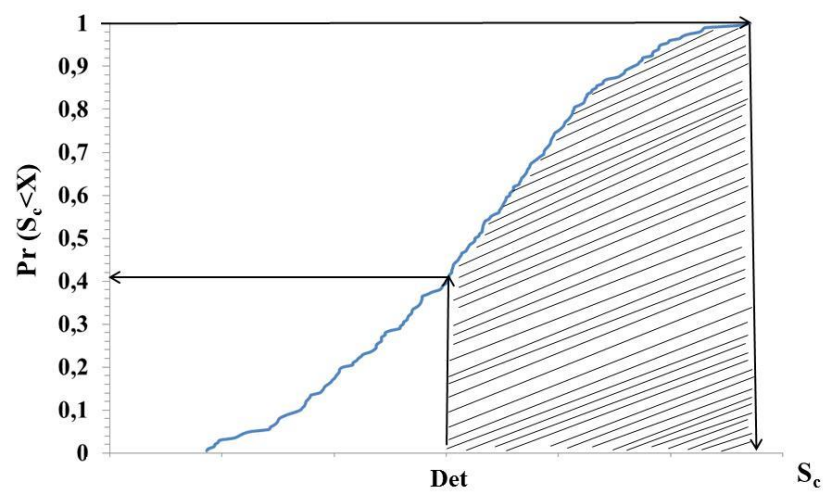

Figure 2: General representation of the cumulative distribution function for environmental categories of impact $S_{c}$, where Det corresponds to the deterministic value of the impact categories.

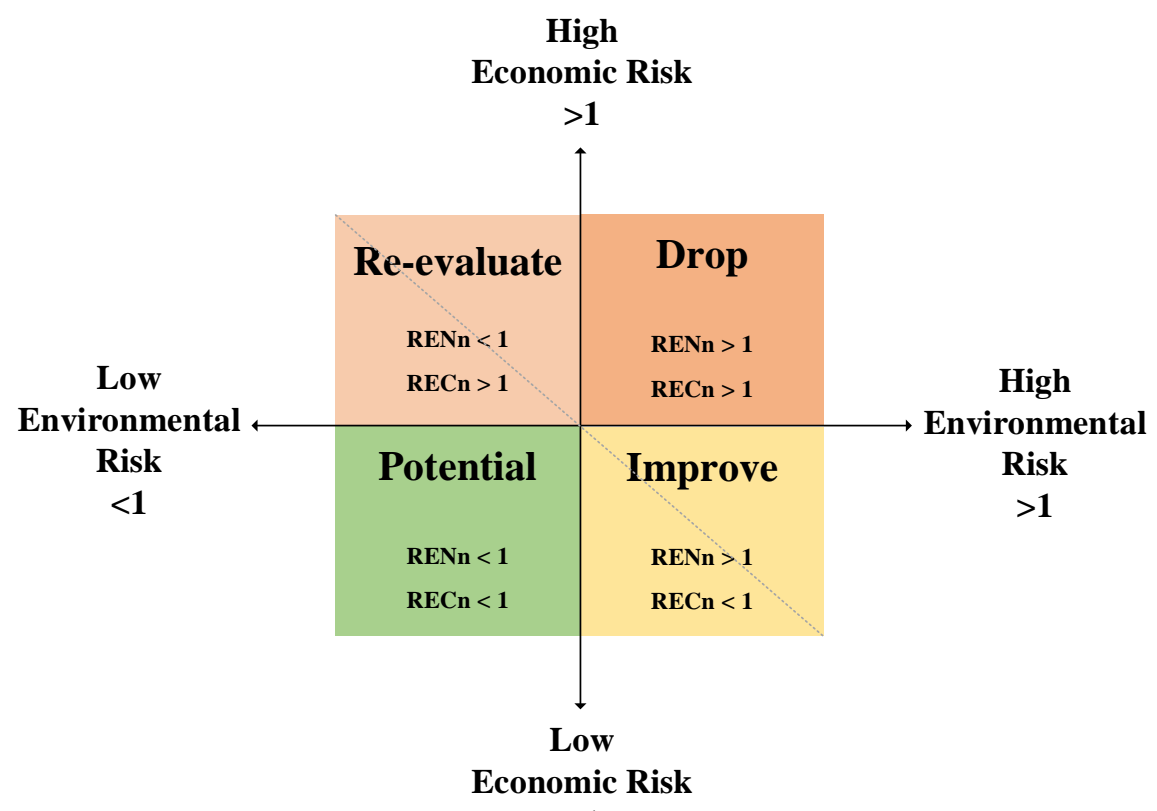

$<1$

Figure 3: Sustainability risk assessment and interpretation matrix. 


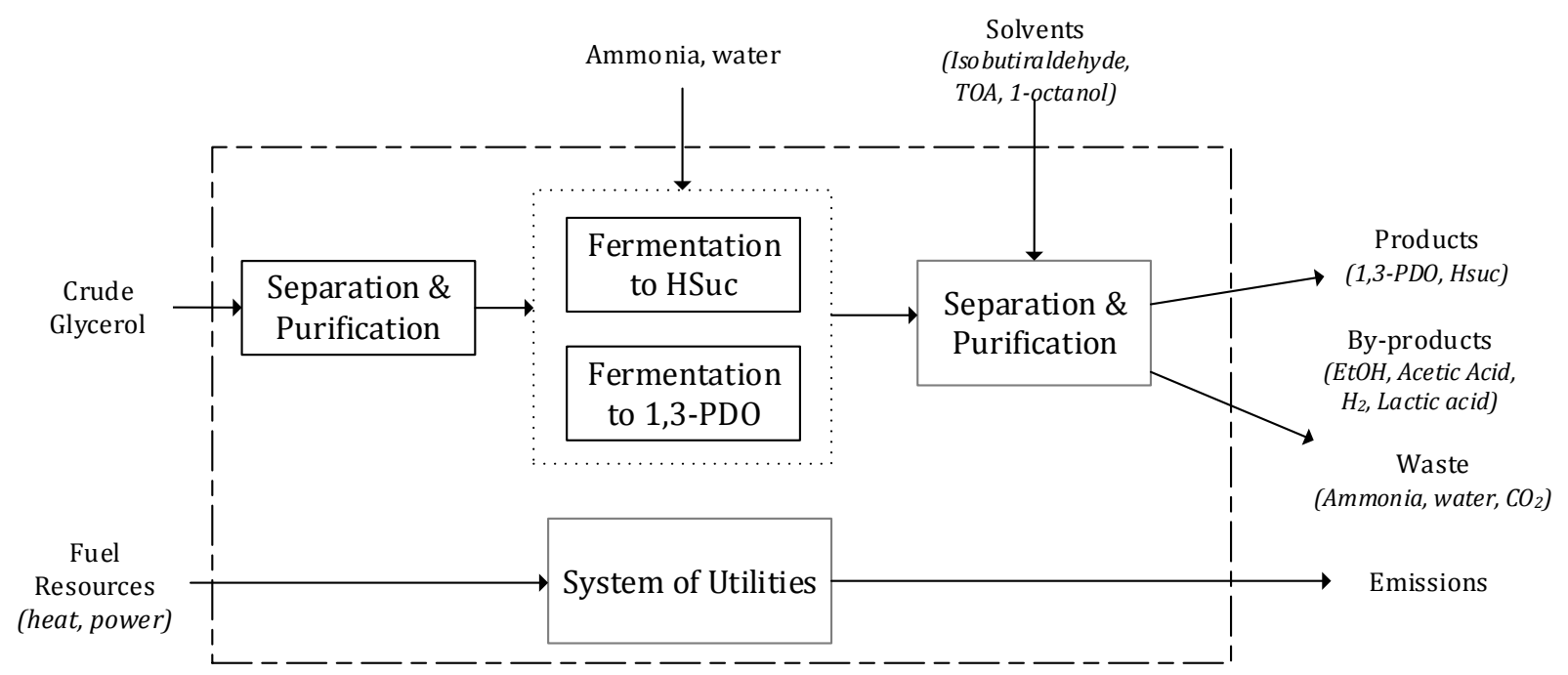

Figure 4: System boundaries to be included in the economic and environmental assessment.

Feedstock historical price $(0.24 ; 0.44)$

Fixed Capital Investment $(-20 \% ;+50 \%)$

Discount rate $(24 \% ; 8 \%)$

Sales Volume $(-20 \% ;+20 \%)$

Product price $(-20 \% ;+20 \%)$

Income tax rate $(-20 \% ;+20 \%)$

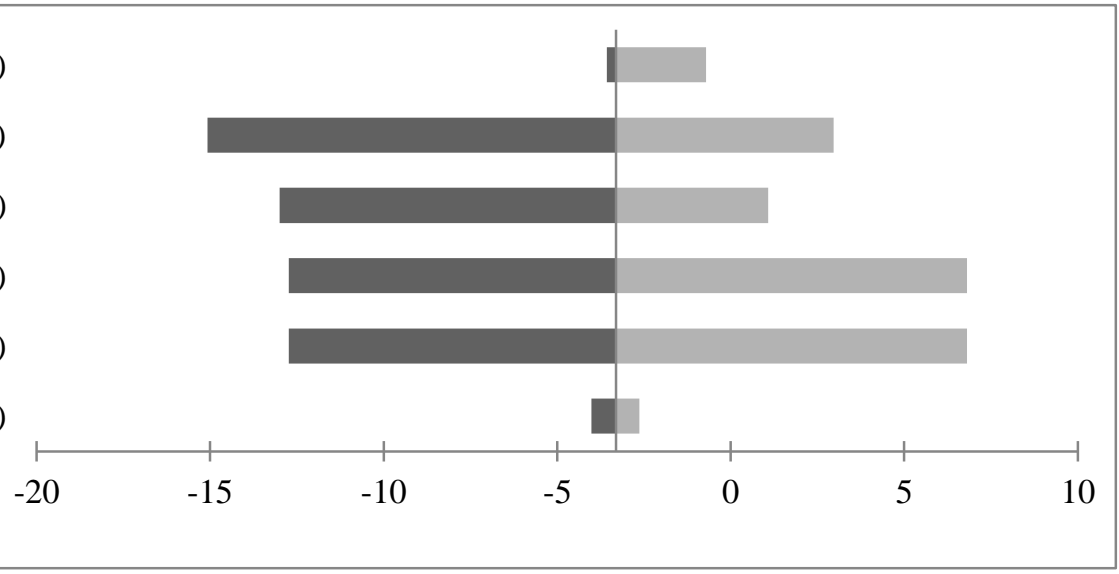

NPV (M\$)

Figure 5: Sensitivity analysis of NPV to variations in key economic parameters. 

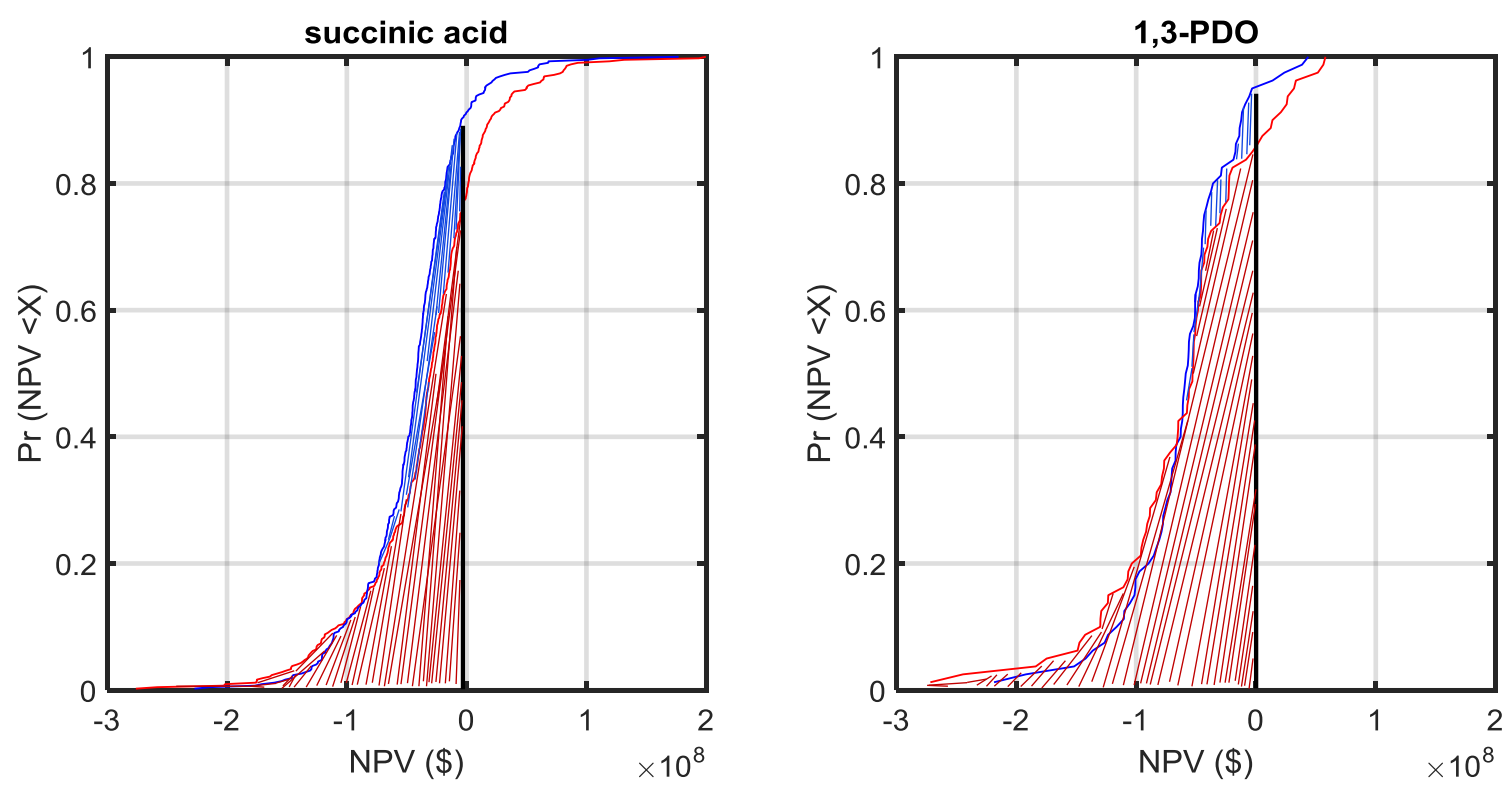

Figure 6: Cumulative distribution function for the succinic acid and 1,3-PDO production from glycerol. The highlighted area represents the risk of the project being non-profitable. Red represents NPV obtained for IRR@10\%. Blue represents NPV obtained forIRR@24\%.

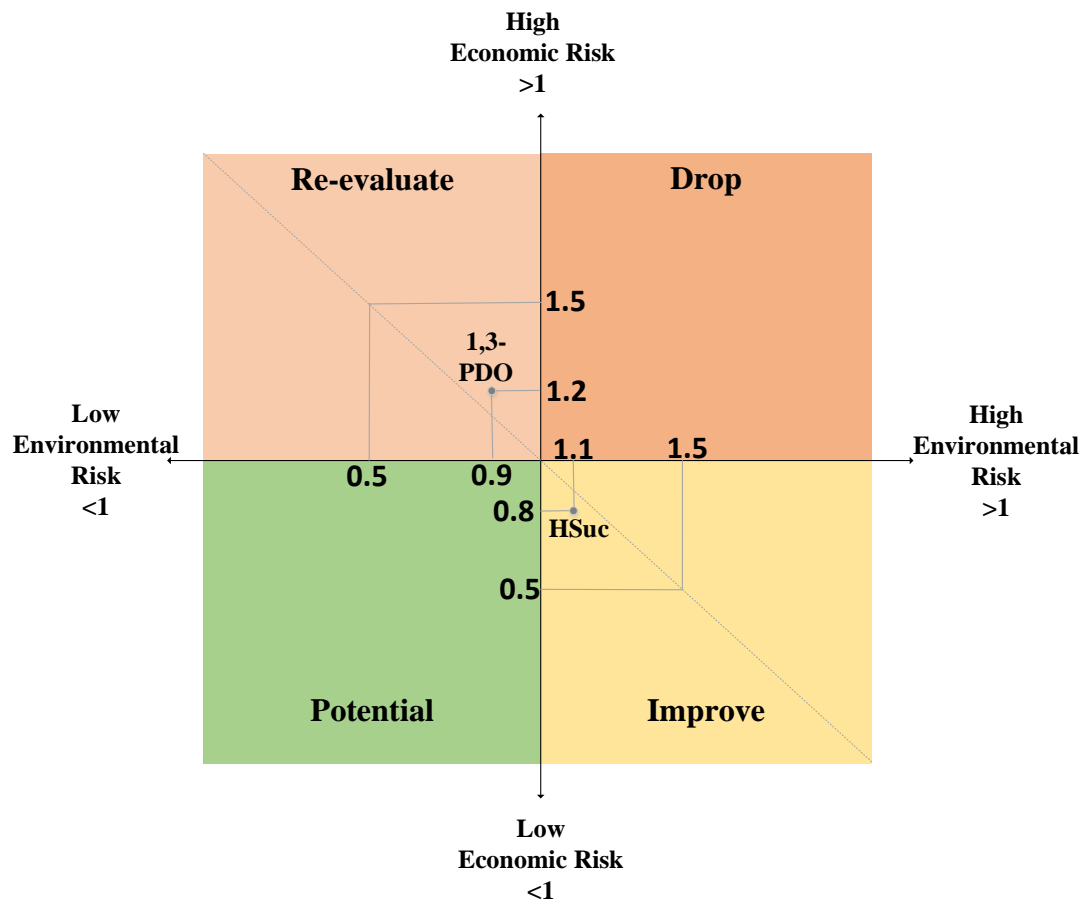

Figure 7: Sustainability risk assessment matrix, where 13PDO and HSuc represent the product positions. 


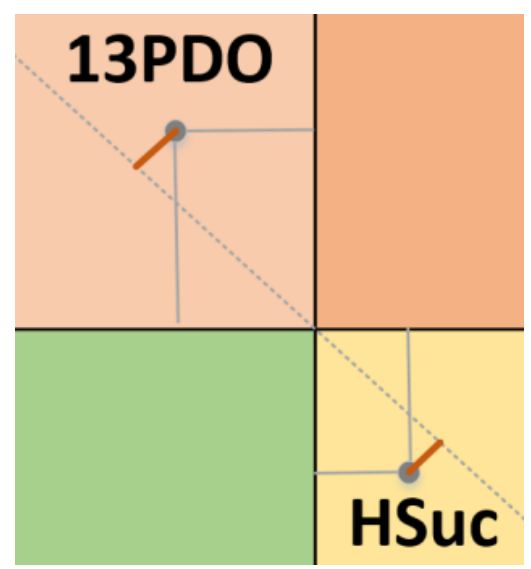

Figure 8: Detail of risk matrix to assess the alternatives' eco-efficiency.

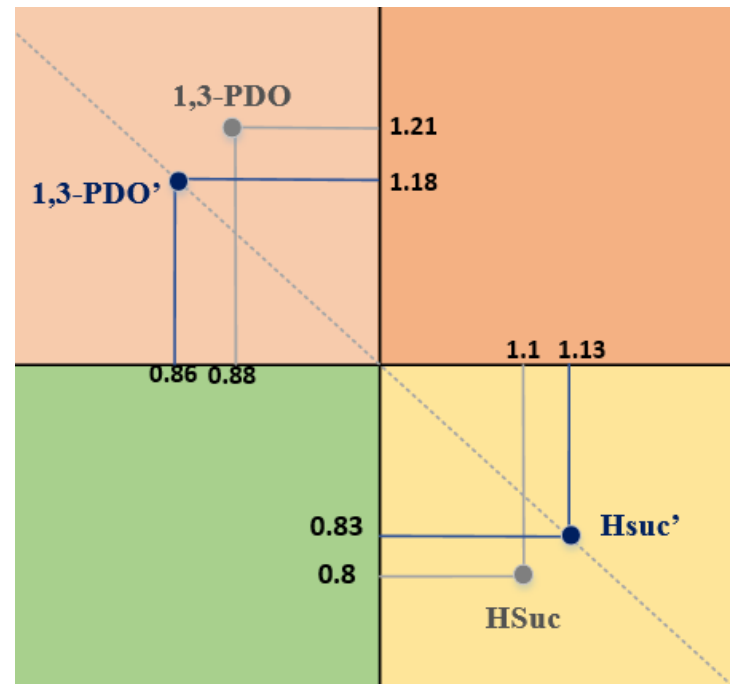

Figure 9: Sustainability risk assessment matrix, where 1,3-PDO, HSuc and 1,3-PDO', HSuc' represent the original and improved positions for both products, respectively. 
Table 1: Midpoint weighting factors given by ECOVALUE08 [39], [40]. Values adjusted for inflation, $\$ 2014$.

\begin{tabular}{|c|c|}
\hline Global warming [\$/kg CO 2 eq.] & 0.33 \\
\hline Acidification [\$/kg SO 2 eq.] & 5.06 \\
\hline Eutrophication $\left[\$ / \mathrm{kg} \mathrm{PO}_{4}\right.$ eq.] & 36.8 \\
\hline Photochemical oxidation formation [\$/kg $\mathrm{C}_{2} \mathrm{H}_{4}$ eq.] & 6.74 \\
\hline Human toxicity [\$/kg $1,4 \mathrm{DB}$ eq.] & 2.03 \\
\hline
\end{tabular}

Table 2 - Summary of the assumptions used for the discounted cash-flow rate of return [35], [46].

\begin{tabular}{|l|c|}
\hline Parameter & Assumption \\
\hline Plant life (years) & 30 \\
\hline Discount Rate (mar) & $10 \%$ \\
\hline Depreciation Period (Years) & 5 \\
\hline Equity & $40 \%$ \\
\hline Loan Interest & $8 \%$ \\
\hline Loan Term (Years) & 10 \\
\hline Construction Period (Years) & 3 \\
\hline \% Spent in Year -2 & $8 \%$ \\
\hline$\%$ Spent in Year -1 & $60 \%$ \\
\hline $\begin{array}{c}\text { Spent in Year 0 } \\
\text { Start-up Time (Years) }\end{array}$ & $32 \%$ \\
\hline $\begin{array}{c}\text { Product production/Feedstock use (\% of } \\
\text { Normal) }\end{array}$ & $50 \%$ \\
\hline Variable Costs (\% of Normal) & $75 \%$ \\
\hline Fixed Cost (\% of Normal) & $100 \%$ \\
\hline Cost Year for Analysis & $35 \%$ \\
\hline
\end{tabular}


Table 3: Average prices and respective standard deviations

\begin{tabular}{|c|c|c|c|}
\hline Products, Chemicals \& Solvents & $\begin{array}{c}\text { Mean } \\
(\$ / \mathbf{k g})\end{array}$ & Std. & Ref. \\
\hline Crude glycerol (60 \% w/w) & 0.42 & 0.048 & {$[47]$} \\
\hline Succinic acid (HSuc) & 2.79 & 0.23 & {$[48]$} \\
\hline 1,3-Propanediol (1,3-PDO) & 2.02 & 0.35 & {$[48][49]$} \\
\hline
\end{tabular}

Table 4: Estimation of the purchased capital cost to be used for the factorial methodology (updated to 2014 prices by using the appropriate CEPCI); and the remaining needed parameters for NPV and MSP calculation [28].

\begin{tabular}{|c|c|c|c|c|c|c|c|c|c|}
\hline products & $\begin{array}{l}\text { Production } \\
\text { rate (ton/y) }\end{array}$ & $\begin{array}{c}\text { Purchased } \\
\text { capital cost, } \\
E^{\prime} \\
(M M \$)\end{array}$ & $\begin{array}{c}\text { Fixed capital } \\
\text { investment, FCI } \\
(M M \$)\end{array}$ & $\begin{array}{c}\text { Total product } \\
\text { cost without } \\
\text { depreciation, } \\
\text { TPC } \\
(M M \$ / y)\end{array}$ & $\begin{array}{c}\text { Utilities } \\
(M M \$ / y)\end{array}$ & $\begin{array}{c}\text { Sales } \\
(M M \$ / y)\end{array}$ & $\begin{array}{c}\text { Averag } \\
e \\
\text { Price } \\
(\$ / k g)\end{array}$ & $\begin{array}{c}N P V \\
(M M \$)\end{array}$ & $\begin{array}{c}M S P \\
(\$ / k g)\end{array}$ \\
\hline $\begin{array}{c}\text { Succinic } \\
\text { acid }\end{array}$ & 2464 & 5.079 & 23.914 & 3.863 & 0.289 & 6.87 & 2.79 & -3.3 & 2.98 \\
\hline 1,3 PDO & 2312 & 14.092 & 21.28 & 3.940 & 0.899 & 4.66 & 2.02 & -6.7 & 2.43 \\
\hline
\end{tabular}

Table 5 - Key economic factors under variability for sensitivity analysis of the DCFR model.

\begin{tabular}{|l|c|c|c|}
\hline & Data Sources & $\begin{array}{c}\text { Lower limit } \\
\text { (\% of the baseline) }\end{array}$ & $\begin{array}{c}\text { Upper limit } \\
\text { (\% of the baseline) }\end{array}$ \\
\hline Product price & {$[36]$} & $-20 \%$ & $+20 \%$ \\
\hline Feedstock price & {$[36]$} & $-10 \%$ & $+30 \%$ \\
\hline Fixed Capital Investment & {$[56]$} & $-20 \%$ & $+50 \%$ \\
\hline Discount rate & {$[36],[57][$ this work] } & $8 \%$ & $24 \%$ \\
\hline Income tax rate & {$[58]$} & $-20 \%$ & $+20 \%$ \\
\hline Sales Volume & {$[35]$} & $-20 \%$ & $+20 \%$ \\
\hline
\end{tabular}


Table 6 - Summary of results for the calculation of economic risk for succinic acid and 1,3-PDO.

\begin{tabular}{|c|c|c|}
\hline & Succinic Acid & $\mathbf{1 , 3 - P D O}$ \\
\hline Frequency of selection & $420 / 500$ & $80 / 500$ \\
\hline $\operatorname{Pr}(\mathrm{NPV} \leq 0) @ I R R 10 \%$ & 0.7857 & 0.8625 \\
\hline $\operatorname{Pr}(\mathrm{NPV} \leq 0) @ I R R 24 \%$ & 0.9119 & 0.95 \\
\hline Risk@IRR10\%(M\$) & 41.22 & 62.68 \\
\hline Risk@IRR24\%(M\$) & 48.40 & 65.24 \\
\hline
\end{tabular}

Table 5: Summary results for the joint risk assessment,

\begin{tabular}{|c|c|c|}
\hline & Succinic Acid & $\mathbf{1 , 3 - P D O}$ \\
\hline Risk $_{\text {env }}(\mathrm{M} \$ /$ lifetime $)$ & 53.85 & 47.66 \\
\hline$\left(R E C_{n, j}, R E N_{n, j}\right)$ & $(0.80 ; 1.1)$ & $(1,21 ; 0.88)$ \\
\hline $\mathrm{R}$ & 1.39 & 0.73 \\
\hline$\left(R E C^{\prime}{ }_{n, j}, R E N^{\prime}{ }_{n, j}\right)$ & $(0.83 ; 1.13)$ & $(1,24 ; 0.91)$ \\
\hline
\end{tabular}

